\title{
Léxico y toponimia de la caza de fieras en Asturias. Paisaje, construcciones y costumbres en torno a las antiguas trampas de caza
}

\author{
por David Ordóñez Castañón ${ }^{\mathrm{I}}$ \\ $y$ Xulio Concepción SuÁrez ${ }^{2}$
}

\section{INTRODUCCIÓN}

\begin{abstract}
CON EL presente trabajo pretendemos profundizar un aspecto concreto de la zootoponimia asturiana: el de la caza de fieras. Una actividad comuñera, entre otras, con la que los nativos pretendían desterrar, o al menos equilibrar, aquella fauna salvaje que causaba daños en el ganado doméstico, principal medio de vida en las precarias economías familiares de las aldeas de antaño. Consistían estas trampas para la captura de aquellos animales considerados perniciosos (lobos y osos, sobre todo) en unas rústicas construcciones de diversas tipologías (según los concejos, la morfología del terreno, los materiales disponibles, etc.), realizadas con los recursos más elementales al alcance del vecindario de los pueblos.
\end{abstract}

${ }^{1}$ Universidad del País Vasco UPV/EHU

${ }^{2}$ Real Instituto de Estudios Asturianos 
El problema de su investigación reside, sobre todo, en el hecho de que los informantes van faltando de los pueblos por razones diversas $y$, en muchos casos, las trampas permanecen casi olvidadas en los montes: a menudo solo encontramos sus ruinas, más o menos conservadas, pero en ocasiones únicamente quedan los nombres para contarlo. En esta situación, el rastreo de la toponimia puede ser una importante herramienta para hallar posibles vestigios de este tipo. En un segundo análisis, la toponimia (la etnotoponimia, la etnolingüística, en rigor) también puede ayudar a precisar costumbres y modos de uso de dichas trampas a través del léxico de la zona en boca de los lugareños.

En otros casos, este campo del lenguaje toponímico asturiano no se refiere, directamente, a trampas o métodos de caza, sino a ciertos aspectos etológicos de estos animales: lugares de paso frecuente, de avistamiento, de espera, de reproducción, etc. Por el contraste con otros léxicos y toponimias más allá de estas montañas, vamos deduciendo de paso todo un conjunto etnográfico que va más allá de lo puramente local. El estudio multidisciplinar se hace imprescindible, por ello, para llegar a conclusiones definitivas.

\section{LA TOPONIMIA COMO FUENTE DE INFORMACIÓN PARA EL ESTUDIO DE VESTIGIOS ARQUITECTÓNICOS Y ARQUEOLÓGICOS EN EL MEDIO RURAL}

En arqueología, el análisis de la toponimia ha sido tradicionalmente una valiosa fuente auxiliar, especialmente en estudios sobre el poblamiento y los usos del territorio rural. No obstante, también son muchas las voces críticas que cuestionan su uso, haciendo hincapié en las debilidades que presentan aquellas interpretaciones históricas realizadas casi exclusivamente sobre registros toponímicos. Sin embargo, admitiendo ciertas limitaciones, como la falta de cronología, y asumiendo posibles imprecisiones espaciales, la toponimia constituye una herramienta fun- 
damental para comprender la historia y estructura del paisaje rural y sus elementos. Hay que tener en cuenta que, en zonas como la que nos atañe, no se han producido importantes cambios agrícolas o poblacionales, lo que ha permitido el mantenimiento hasta hoy de la toponimia medieval (Fernández, 2006, págs. 49-50).

Por tanto, la prospección toponímica resulta fundamental para hallar y analizar tanto las antedichas estructuras-trampa empleadas antaño para capturar animales, como otros elementos arquitectónicos propios del espacio rural (molinos, caleros, cuerrias, cabañas, etc.), hoy en día en proceso de abandono y desaparición a causa de los cambios que experimenta el campo asturiano. En esta tesitura, se hace necesario (y urgente) recopilar y documentar tanto los vestigios materiales como los inmateriales, entre ellos los toponímicos, si queremos salvaguardar la memoria histórica de los montes.

Por otra parte, a la hora de abordar el estudio de alguno de estos elementos en un ámbito geográfico amplio, como puede ser la identificación de trampas históricas de caza de fieras en Asturias, el rastreo toponímico es seguramente el método más ágil para obtener indicios de su posible ubicación. En nuestro caso particular, en cuanto a las fuentes consultadas, manejamos la bibliografía a nuestro alcance: diversas cartografías (oficiales y montañeras), los cuadernillos de toponimia de la Academia de la Llingua Asturiana ${ }^{3}$ y el Diccionario etimológico de toponimia asturiana (Concepción, 20I7). Merece la pena resaltar la propuesta metodológica planteada por Llaneza y Torrente (2000) para realizar un

3 Realizamos una revisión completa de todos los cuadernos editados hasta el momento de concluir este trabajo (del n. ${ }^{\circ}$ I al I42), de los que tomamos buena parte de los topónimos que a continuación recogemos. Se trata de una colección de más de un centenar de cuadernillos, de modo que, por motivos obvios de espacio, solo nos referiremos a aquellos de los que se extraen citas textuales. 
catálogo de estructuras cinegéticas. En este proyecto ya bosquejan un banco de topónimos relativos a la caza de fieras.

Sin embargo, esta indagación toponímica es solo un paso previo, que debe ser siempre corroborado por el posterior trabajo de campo (buscando los restos, reconociendo el terreno in situ, recabando testimonios orales y otros indicios) y, si existen, también por otras fuentes bibliográficas y documentales. Hasta el momento, hemos identificado cerca de cuarenta trampas en los concejos centrales de la montaña asturiana (Llena, Quirós, Riosa, Mieres, Ayer...), documentadas a partir de la toponimia.

La interpretación del significado de algunos nombres de lugar, que se repiten en las inmediaciones de dichas trampas, nos permite extraer ciertas pautas comunes, de manera que su significado quizás podría extrapolarse a otros parajes aún no visitados. Tras realizar una exhaustiva revisión de las fuentes, hemos agrupado por familias léxicas aquellos topónimos que guardan relación con la zootoponimia ferina.

FAMilias ETIMOLÓGICAS DE TOPONIMIA CINEgÉTiCA EN AsTURIAS

\section{armá, armada}

La voz armar tiene el sentido de 'preparar una armadía ('armadija') para atrapar diversos animales silvestres'; lat. armata ('trampa'), del verbo armare ('equipar, pertrechar'); de forma genérica, sin referirse a alguna tipología concreta de trampa. En todo caso, abunda en toponimia, aludiendo a lugares estratégicos para la caza. Ya el Diccionario de Autoridades (I726, tomo I) recoge la voz armada como «las mangas de gente que se ponen en las cazas de las fieras para espantarlas, y que vayan a salir por la boca donde están los cazadores».

En el caso de Armá en Lena, se conserva, muy deteriorado y camuflado por los helechos, un pozo justo bajo el Sosellar (apenas unos metros por 
debajo de la carretera). Hoy se llama El Puzu Caliru Viiyu por lo que quizás pudo ser utilizado luego para otras funciones (como calero), o bien toma tal nombre de algún horno próximo. Por otra parte, toda la zona de Armá fue, y sigue siendo, lugar estratégico de paso de animales monteses (lobos, osos, raposos...) que salen de los bosques de Riosa a la falda del Aramo y cruzan hacia los del Mofusu, a la falda de Llago. También queda, para confirmarlo, el Puzu Llobos de Chamixé, justo bajo los altos de Armá, a pocos metros por la ladera riosana (Concepción, 2017, pág. 284 y pág. 915).

El mismo origen podrían tener lugares parecidos: Armá (Llangréu, cerca del pueblo de Pozobal), L'Armá (Turón), L'Armada (Entrialgo), A Armadía (Barandón, Ponticiella), Armiello (Turón), y semejantes por el paisaje asturiano de montaña.

No todos los lugares con esta base toponímica deben el nombre a la caza de animales en el monte, pues a veces solo se refiere a las armaduras: verdaderos entramados de piedra y maderas, en las mismas pendientes de las rocas o en el paso de unas a otras evitando los precipicios; ambas aéreas adosadas a las paredes rocosas, pequeños puentes sobre arroyos más o menos profundos, etc. Incluso, en algún caso, puede tratarse de una voz homonímica prerromana, sin nada que ver con este campo cinegético.

\section{calecho, caleyu, caleyón}

Muy abundante es el campo léxico asociado a los caleyos: lat. calliculum, a partir de callem ('senda, sendero, vereda'), en principio, aplicado a lugares de paso. Su referencia a la caza es evidente en buena parte del asturiano: un caleyu, caliyu, caleichu, calecho... se refieren a los callejos, cerrados por paredes convergentes de piedra, estacas o cebatos ('entramados de varas'), que se formaban en las batidas de los pueblos (muy documentadas), para conducir a los lobos hacia el pozo, de forma irreversible. En la documentación histórica, el término caleyo o calello aparece recogido al menos desde el siglo XVI (Uría, 1976, págs. 308-310). 
En muchos de estos parajes, las antiguas prácticas cinegéticas han sido confirmadas, bien mediante la tradición oral o a través de documentos históricos. Tenemos, en Lena, el caso del Monte'l Caliyu, justo debajo de la Pena la Portiella, donde también hallamos un pozo bien conservado. Según la memoria oral, en ese punto se levantaba un cierre que «se hacía de varales, sebe y alambrera» para conducir al lobo hacia el foso durante la montería ${ }^{4}$.

También en Lena, aunque en pleno centro urbano de La Pola, se halla El Caleyón de los Lḷobos (Concepción, 1990, págs. 752-753). Parece referirse a un vado del río Lena, en las llamadas Pedrosas, por donde los lobos cruzaban en épocas de menor caudal, cuando descendían de la vertiente del Aramo y pasaban hacia los altos de Ranero, limítrofes con los montes alleranos. Los lugareños aprovechaban dicha circunstancia para disponer trampas en este punto.

Entre Riosa y Mieres se conserva, al pie del Picu Llosoriu, un excelente pozo cerca de Campa Braña, donde se dice Los Caleyinos. Este ejemplo es seguramente el mejor documentado de la zona, gracias al «acuerdo de reparación del caleyo de Riosa", protocolo notarial fechado en I629, por el que los representantes vecinales contratan el arreglo de la empalizada (Montero, 1996, págs. 20I-202).

Encontramos otros casos similares en los concejos del entorno: en Ayer, cerca de Las Moyás (Felechosa), hallamos la Vallí Caliiyu, un empinado canalizo bajo el Puzo Viiyo (Ordóñez y Nicolás, 20I7, págs. 28-30). Y en las inmediaciones de La Güeria de Urbiés (Turón, Mieres) damos con los restos de otro foso, junto a la sebe de un prado denominado El Caliyu, cuya situación apunta, nuevamente, al aprovechamiento del relieve para enveredar a las fieras hacia la trampa. Según la cartografía, La Campera del Caleyu y La Fuente del Caleyu (Villaviciosa) se sitúan próximas al Pozu de

4 Testimonio de Manolo el de Espineo, en conversación con David Ordóñez Castañón (26 de junio de 20I6). 
los Llobos (limítrofe con Sariego). En resumen, el topónimo caleyu, caliyu, caneyu, etc. se refiere a la acción de encallejonar hacia el foso al lobo u otros animales, a menudo ayudándose de los accidentes orográficos y valiéndose de las referidas estacadas o sebes.

En estos casos que acabamos de nombrar, todos en la zona central de Asturias, al hablar de caleyu nos referimos a aquellas construcciones compuestas por dos paredes (de diversos materiales) que convergen en un pozo. Según la clasificación morfoestratégica de Torrente, Llaneza y Álvares (20I4, págs. I42-I62), esta tipología se corresponde con la familia de las trampas «angulares» (familia v). Sin embargo, en el occidente asturiano, el término calecho también se refiere a trampas denominadas «de corral» (familia C).

Entre otros, tenemos en Cangas del Narcea los calechos de Pena Ventana (también conocido como Calecho de Oubachu), Sierra del Pando y Valláu; en Degaña los calechos de El Rebollal, El Corralín, Piedrafita (en el lugar de Teso Calechu) y Calechu Trabáu; y en Ibias, el Calechu de Villardecendias, todos ellos trampas de corral (Salvador y Porcu, 20IO, págs. I2-3I).

En definitiva, abundan repartidos por toda la geografía asturiana parajes toponímicos con tradición oral de trampa lobera (sea cual sea su tipología), como El Calechu (en Degaña, Somiedo y también en Ḷlaciana y Palacios del Sil, León), además de otros donde quizás existan vestigios: El Bosquín de Caleyu (debajo de El Cuetu Llobedu, en la zona de El Caleyu, Inguanzo, Cabrales), La Campa Caliyu (Llangréu), El Prau Caleyu, Prau'l Caliyu o Prucaliyu (en varios concejos), Monte del Caleyu (también en varios municipios), El Caleyo del Foxo (Pezós), Pena el Caleyo (Tineo), entre otros.

Otros muchos, como El Caleyón (Ayer, Carreño, Grao, Llaviana, Mieres, Proaza...), Los Caleyones (Llanes, Mieres, Sariego...), El Caleyu (Cabrales, Cabranes, Cangues d'Onís, Colunga, Grao...), se refieren más bien a prados, caserías o simples caminos, por lo que puede tratarse, en la mayoría de casos, de aquellos 'caminos estrechos, sendas, senderos', en el sentido original de la voz romance, sin aludir a trampas cinegéticas. 


\section{caneyu}

Un caneyu, al igual que un caleyo, es un 'camino estrecho' entre sebes por el que se conducían a los animales en las monterías para que cayesen a un pozo. Tal vez diminutivo latino de calliculum, a partir de callis 'senda, sendero'.

Tenemos, muy claro, El Pozu Caneyu, uno de estos hoyos lobales que se tendían a dichos animales bajo Pozobal, en el camino de Següencu hacia Najuentes (Cangues d'Onís). Otros, si bien no podemos confirmarlos, son posibles, como El Caneyu, en Gobiendes (Colunga); El Caneyu Vieyu y Los Caneyos, en Óbana (Piloña); La Vega'l Caneyu, sobre La Pena Rosques, junto a Caliao (Caso); y quizás El Caneyu, en Valdetañes (Caso). Otros ya más dudosos: Los Caneyos (en varios concejos), El Canellín, El Canillín, etc.

\section{caón}

Sufijo aumentativo del lat. cavum ('cóncavo, hueco, hondo'). Es en realidad un orónimo que se refiere a un paraje empozado entre montañas. Precisamente, este relieve cóncavo resulta idóneo para disponer una trampa angular, situado el pozo del caleyo en el punto donde converge la vaguada. Se conserva, solo en parte, la trampa de El Caón (Caso, Sobrescobio), cerca del pueblo de Llaínes/Ladines. Queda el dicho: «El Caón / onde mataben los llobos a traición». Quizás también El Caón, en Óbana (Piloña).

\section{carreiro, carrera}

Un carreiro es, en principio, un sendero: un camino estrecho marcado con el tránsito frecuente de personas o animales; desde la acepción 
inicial de 'paso de los carros' (lat. carrus, carrārius, abreviación de via carraria 'camino de carros' -registra Corominas-), se aplicaría al paso de cualquier transeúnte capaz de hacer huella. Por esta razón, los lugareños observaban en el monte, sobre todo, el paso de animales propios y ajenos, lo mismo en previsión de la caza (corzos, robezos, melones...), que de otros considerados peligrosos para el ganado (lobos, osos, raposos...).

No obstante, la calle o "carrera» es también el espacio comprendido entre las empalizadas de un caleyo, por donde las fieras eran conducidas hacia el foso (Arellano, I745, pág. 138). En estos casos, el término carrera parece aludir a la persecución del animal durante la montería, atendiendo a la acepción de 'acción de correr las personas o los animales'. Debe tenerse en cuenta que antiguamente se hablaba de «correr el monte» para referirse a las batidas de lobos u osos, siendo habituales en los documentos históricos expresiones tales como "corridas de fieras»" Incluso en el citado acuerdo del caleyo de Riosa, este se describe como un «caleyo corredizo».

\section{caza}

Voz procedente del lat. capěre, lat. vg. captiare, en principio (s. XII), con el sentido de 'perseguir, coger'; el mismo Diccionario de Autoridades (I726) define caza como «La acción de buscar, seguir, acosar y perseguir aves o animales, para rendirlos y sujetarlos el hombre a su dominio, lo

s En el Libro de Acuerdos del Ayuntamiento de Oviedo se recoge en repetidas ocasiones la expresión "correr el monte» en referencia a las batidas de lobos, tal y como documenta Juan Uría Ríu (1976, págs. 310-316). En las Ordenanzas Generales de la Junta del Principado de Asturias encontramos también "correr los montes y limpiarlos de las fieras» (Asturias, I974, art. 48, año I78I), mientras que en las ordenanzas que regulan la organización de la parroquia de Soto (Ayer) se habla de "correr la montería» (García, I963, págs. I7I-I72). Finalmente, en un pleito de pastos entre Lena y Quirós, mantenido en el s. XIX, leemos que «las parroquias de La Pola y Muñón Cimero hacen con su montero mayor la corrida de fieras hasta La Covertoria y Collada de Llanuces», refiriéndose un poco más adelante a la «correría de las fieras». 
que se executa con armas, lazos, trampas y otras invenciones». El mismo diccionario define cacería como "Diversión y festéjo que se dispóne para ir à caza ò montería, en que concurren muchos, llevando todo lo conveniente para su divertimento y regalo». De modo que, en el uso de los lugareños, la caza tenía por objetivo la observación, búsqueda y captura de animales del monte con destinos diversos, pero con estrategias locales. No obstante, es un topónimo raro, del que apenas hallamos ejemplos (tal vez Cazalumbu, Llaviana).

\section{chorco, chuerco}

En determinadas zonas del oriente de Asturias y, sobre todo, en la montaña de León, un chorco o chuerco es una empalizada que se hacía para cazar lobos, equivalente al caleyu de la zona central (familia v). El más conocido es el chorco de Corona, en Cordiñanes, en la comarca leonesa de Valdeón. En Asturias queda el Chuerco de los Llobos en Amieva, parcialmente conservado y reconstruido. Quizás también El Chorcu, en Samartín del Rei Aurelio. Ya en el uso cántabro, es un simple hoyo en tierra para sembrar algunos productos; lat. sŭlcus ('surco').

\section{ciarru, cierru}

Un cierru, ciarru, zarru, zarro..., es un cierre con varas, varales, verdiones, postes, pertegones..., según los casos y objetivos; lat. serare ('cerrar'). En algunos casos, solo la toponimia circundante nos inclina a asimilarlos con trampas lobales (en relación con las empalizadas usadas para acorralar a los animales); en todo caso, se recogen solo como hipótesis ${ }^{6}$.

\footnotetext{
${ }^{6}$ Algunos casos hipotéticos, por interpretación de la toponimia inmediata, podrían ser El Ciarru'l Caleyu, en Llatores; El Ciarru, en Uviéu (cerca de La Cueva 'I Raposu); El Cierru los Pozos; El Cierru Vieyu, en Sariego...
} 
corral

Se considera ya voz celta, ${ }^{*}$ kor-r- ('construcción circular, cercado'), en uno de tantos derivados asturianos: corro, corra, cuerra, cuerria, corrá, acorrar, corralá, corralón..., siempre con el sentido de 'espacio cerrado', con piedra casi siempre, para distintos usos ganaderos, agrícolas, humanos..., lo mismo en el poblado que en los montes y las brañas. En la clasificación morfotipológica de Torrente, Llaneza y Álvares (2014, págs. I42-I62), estas estructuras componen la familia «C». En Asturias es más habitual conocer este tipo de trampas como cousos (que veremos a continuación), o cortinos (por ejemplo, el Cortín dos Lobos de Villardecendias), aunque nos consta el Calechu de El Corralín (Degaña) y el Corral de los Lobos (Ibias). También hallamos algún paraje de interpretación dudosa como La Corrá del Llobu (Teberga), El Corral del Rapusu (Llaviana), Los Corrales (Degaña) o Las Corradas del Calechu (Palacios del Sil).

\section{couso, couselo}

Del lat. cŭrsüm ('carrera, curso de agua, cauce'). Podría pensarse, quizás, en aquel cercado en el que se «corren las fieras» (vid. carreiro, carrera), como en los cosos taurinos (recinto para la lidia), aplicado al uso cinegético artesanal. En la zona más occidental asturiana, un couso es un recinto para capturar lobos que consiste en un corral de mampostería de entre dos y tres metros de altura, rematado con losas dispuestas formando un voladizo interior. Dentro del recinto se colocaba un cebo vivo o muerto para atraer al animal, que una vez había accedido no podía salir. Estas trampas pertenecen a la antedicha familia morfotipológica de los corrales.

Existen diversas estructuras de este tipo en los concejos occidentales de Asturias. Entre ellas, el Couso da Campa, en Pelorde, y el Couso 
de Vallúa (ambas en Pezós); el Couso de Bustelo (Illano); el Couso de Collada y el Couso de Lago (Allande) y, presumiblemente, El Couso en Trabada (Villayón). Otros parajes, aún no corroborados, serían El Couso (Boal, Allande...), El Cousu (Ḷlaciana), O Couso (Ibias, Taramundi), Couselo (A Veiga, Castropol), El Monte Couso (Ozcos), Las Penas del Couso (Cangas del Narcea), Rego do Couso (Grandas de Salime), etc.

\section{escucha, escuchairu}

Derivados de auscultāre ('escuchar'), *auscultatarium, con sufijo locativo -ariu (el lugar adecuado para escuchar). En algún caso, podría referirse a antiguas costumbres relacionadas con el acecho de la fauna en algún punto estratégico para la caza, o bien aludir a determinados sitios frecuentados por ciertos animales, en los que sería más frecuente escuchar sus sonidos. Ambas interpretaciones las recogemos de los lugareños de Zurea (Ḷlena), sobre el paraje llamado L'Escuchaíru’.

Para unos, el topónimo se refiere a la existencia de un antiguo «cantadero» de urogallos, ya desaparecidos de estos hayedos (Ordónez y Jové, 20I6, págs. 28I-282). Empero, también admite una segunda interpretación, más acorde con la existencia cercana de una trampa para la caza de lobos, según la cual, este sería un punto estratégico de espera (de atisbo,

7 El Picu L’Escuchaíru es el crestón calizo sobre la ladera del monte que asciende desde Valle Zurea (Lena) hacia los altos de Prociles y Monte Cibiello (o Fidiello). El lugar de L'Escuchaíru era la zona de pastos carbizos más aprovechada para la vecera (el rebaño comunal), por encontrarse relativamente cerca de ambos pueblos, Valle y Zurea. Toda esta zona era y sigue siendo lugar preferido por los lobos para el paso entre el Monte'l Mofusu (tupido hayedo sobre Tablao) y los hayedos de Las Cangas, Las Porqueras y El Barral... La prueba está en que a pocos metros de L'Escuchaíru, en Cibiello, se conserva el llamado Puzu los Lḷobos, hoy protegido y mejorado en parte. Todo este monte, en parte hayedo, acebales..., era también lugar preferido de corzos, xabalinos..., por lo que se espiaba la caza al mismo tiempo. De ello nos daba cuenta Cándido el de la Caleya, vecino de Zurea (Ḷlena), quien llegó hasta los noventa y pico años con una memoria preclara (Concepción, 2017, pág. 384). 
control) de diversos animales del monte; al tiempo que se curiaban las cabras y ovejas en las carbas, el pastor de la vecera tenía que controlar desde la mañana la presencia o el paso de lobos, osos o raposos. El pastor se colocaba en la peña y escuchaba ruidos, pasos, aullidos. Y, si había peligro, avisaba a su modo a los vecinos del poblado en el fondo del valle o en las caserías cercanas (con silbidos, voces o signos acordados).

\section{estaca, estaquera}

Se supone voz derivada del gótico *stakka, a juzgar por el anglosajón staca; neerlandés staake; sueco stake. En asturiano, una estaca es un bastón de madera más o menos grueso y corto, según los usos; sirve, sobre todo, para cerrar las fincas con pertegones (varas bastante más largas, delgadas, muy flexibles a la hora de tejer la xebe, el seto artificial); una estaquera es un cierre parecido, pero donde se colocan varales, en lugar de pertegones: es decir, palos largos también, pero más gruesos, resistentes, fendios (abiertos) al medio para aprovecharlos mejor y para que resulten más duraderos. En algunos casos, estos topónimos pueden designar simples límites, pero en otros parecen referidos con claridad a las palizadas que conformaban las alas de los caleyos, como podría ser el caso de Las Estacas de La Cortina, donde está el pozo lobal de Los Molares.

$$
\text { foyu, foxo, fuexu }
$$

Un fuexu, fueyo, fueyu, fuixu (o jou, ju, joón, jobón en zona oriental), es un terreno en hondonada, zona más o menos empozada, muy aprovechada por los ganados y animales del monte para resguardarse en días de viento o temporal. Del lat. *foveum, a partir de fovĕam ('hoyo, excavación'). Sería el caso del Foyu’l Raposu (San Román, Sariego), un agujero en el que los zorros buscaban refugio. En el caso del Foyu los 
Gatos de Colunga (cerca de Cordobana, Gobiendes), podría ponerse en relación con los gatos monteses, el gatu algaire (Felis sylvestris).

En Galicia, «foxo do lobo» es la denominación más extendida de las trampas para lobos. Pérez López (20I0, págs. 405-408) relaciona las primeras referencias a estas construcciones en diversos documentos medievales, leyéndose, según el caso, fogo lopare, fogium lobalem, fogium lobal $y$, en repetidas ocasiones, fogium lupalem. Según Moralejo Laso (I977, págs. I37-I43, en el capítulo "Fogium lupale” y sus actuales derivados gallegos»), fogium sería «una falsa latinización medieval de un vulgar foio o fojo, que en realidad proviene de la forma del latín vulgar foveum por fovea». Este sería el origen de muchos de los topónimos alusivos a la captura de lobos, especialmente en la zona de Lugo: Feirobal, Fillobal, Foilebar, Fiorobal, Follabal, Follobal, entre otros.

Aunque no localizados, tal vez se encuentren topónimos similares en la parte más occidental de Asturias, si bien El Foxo, en Pezós, es dudoso. Fueyu, Fueyos, Fuexu, Fuexos, Foxacos, Foyu, Foyos, etc., son nombres muy abundantes en toda la geografía asturiana, pero, en la mayor parte de los casos, parecen referirse simplemente a terrenos empozados. No obstante, en algunos casos comprobados, como en El Foyu Valloberu de Villaviciosa, hay una referencia lugareña evidente a la caza de lobos ${ }^{8}$.

furáu, furacu, furoco, juráu, juracu

Los agujeros tienen muchas referencias en cualquier paisaje, con usos muy distintos, desde simples orificios naturales en las rocas, hasta sumideros de aguas, excavaciones romanas... Lat. forare, foratum ('perforado, horadado'). Para algunos casos se podría pensar en trampas de animales,

Del Pozu Valloberu, en Puelles, «se diz que va munchu tiempu escorríen animales pa que se derribaren nél; güei ta tapáu» (Villazón, 1993, pág. 9). 
como en Furdalanos: tal vez, del lat. foratum, más gótico alans, luego, alano ('lebrel'); Furdalanos es la zona bajo Porciles, en los altos de Zurea (Llena), muy propicia siempre, lo mismo a los xabalinos del monte que al paso de los lobos tras los jabalís y los corzos, en aquellos altos del tupido hayedo del Monte'l Mofusu, tan propicio a unos y a otros hasta la fecha. Al lado está Cuitu Llobos, no por casualidad.

No obstante, la mayoría de lugares con esta base de los agujeros y furados han de tener referencias diversas: El Monte del Furoco de Pezós, o el mismo Montefurado de Allande, al otro lado del Puerto'l Palo, con tantas excavaciones de las famosas minas romanas en torno a La Fana Freita, El Valledor... Finalmente, otros son evidentes ventanas, grietas, pozos naturales o artificiales en las peñas o en el terreno: Penafurá, Penafurada, en algún caso como calculada estrategia de vigilancia al par de las vías romanas.

gatu, gatos

El Picu’l Gatu, en Teyego (Ribera); El Foyu los Gatos, en Colunga: bajo El Pienzu; La Sienda'l Guetu: vereda muy estrecha en Las Pena los Infiernos, sobre Pelluno (Aller) subiendo a Penamea; El Monte'l Gatu (Cangas de Narcea); La Gatera (Mieres); Les Gateres (Riosa); La Concha’l Gatu (Peñamellera Alta); La Pena’l Guetu, La Cueva'l Guetu: sobre La Frecha (Llena). Parecen todos aludir a lugares de avistamiento o refugio del gato montés (Felis silvestris).

No sabemos exactamente las técnicas de caza: tal vez, a base de redes, lazos de material diverso, trampas en los senderos, en las cuevas... El caso es que quedó la referencia a los gatos: latín tardío cāttum ('gato salvaje'), y allá por el s. viI, 'gato doméstico'. 


\section{llobos, llobu, lloberu}

Es el término toponímico más frecuente en relación con las trampas loberas. En ocasiones, el topónimo especifica la forma de caza, por ejemplo, entre otros, El Pozu los Llobos, en Sariego, está muy documentado oralmente?. O, similar, El Foyu Lloberu (Villaviciosa): con arraigada tradición oral de que allí se corrían animales para precipitarlos en el pozo. Otras veces, aunque el topónimo no alude directamente a la técnica de caza, podía haber al lado pozos, caleyos u otras trampas. Es el caso, por ejemplo, del Prau'l Lبlubu, junto al pozo de Los Molares (Llena); la Vallí Lluil y La Lloetera (Ayer), en el entorno del Puzo los ḷ̣obos de La Vega'l Taío (Ordóñez y Nicolás, 20I7, págs. 24-27); o El Sierru los Llọobos, en el extremo norte de la Campa Trapa (Riosa), en la que se ubica el pozo de Los Caleyinos.

Por toda la geografía asturiana se diseminan parajes cuyos topónimos aluden a la presencia del lobo (Canis lupus): La Fuente los Llobatos (Cabranes); La Fuente'l Llobu (San Cloyo); El Llobo, Los Lḷoberos, La Faya los Lب̣obos, El Yenu los Llobos (Ḷena); Bras!̣lobos (Ayer); La Pena Lḷobal, El Porllobal (Teberga); La Faya los Lب̣obos, La Masera'l Llobu (Llaviana); La Granda los Llobos (Carreño); La Juente la Lloberiza, Los Llobos, La Juente los Llobos, Sierra de Llobiles (Ponga); Cuetu Llobu (Onís); El Prau'l Llobu (Ardisana, Llanes); El Llọbu la Vallina (Valdés); La Lloba (Candamu); La Llobacha; El Prau los Llobos (en Los Caleyos, Samartín del R. A.); Los Llobatos (Cabranes); Vegalobos (Piloña); La

9 «Pozu onde cazaben los llobos cuando se facíen monteríes, que foi tapáu por una pala cuando se plantaron pinos; sitúase debaxu El Monte Llubines, nel altu onde emboca El Monte l'Osil, ya de Villaviciosa, anque dicen que yera terrén de Sariegu; pal noreste, Fumarea; y pal este del Monte l'Osil. Llámase tamién asina al colláu en terrén comunal onde había un fiensu (I,20. d'anchu y o,6o m d'altura), na llende de Sariegu y Villaviciosa, nel cume La Llomba; y pal norte, Canal» (Friera, 1994). 
Llubil (Colunga); Matallobil (Villaviciosa); Les Llobes (Colunga); El Llobu (Uviéu y Xixón); El Llubiru (Mieres); El Picu Llobu (Santadrianu); El Xerru los Lllobos (Casu); Trasdechobos (Cangas del Narcea), entre tantos otros.

Alguno de ellos podría aludir a la caza del animal, pero en ocasiones solo eran lugares en la querencia de los lobos y las lobas: puntos estratégicos de vigilancia sobre los pueblos, sendas disimuladas, pasos de ríos o de valles; o lugares recónditos a la hora de criar la camada: estas guaridas eran muy observadas por los lugareños, les seguían los rastros, escuchaban sus aullidos de noche, y daban con ellas para quitarles las crías. $\mathrm{O}$, simplemente, observaban bien sus movimientos para comenzar las batidas y conducirlos a las trampas cercanas.

\section{manga}

Es ya voz antigua, aplicada a la caza; así, el Diccionario de Autoridades la define en el s. XviII como «la gente que en las batidas se pone á los lados de la ballesta para enderezar los lobos que intentan reventar por los lados ${ }^{10}$. Del lat. manǔca ('manga larga de túnica'), aplicada a la actividad humana cinegética en forma figurada. En algunos casos comprobados, la voz mangas se refiere a las empalizadas de maderas distintas al final de las batidas, que conducían al animal directamente a los pozos, caso del Chorco de Corona leonés.

Quedan en toponimia nombres como La Manga'l Puzu sobre Parana (Llena), con esa referencia posible a las barreras de cebatos y estacas, o del vecindario del pueblo, para conducir los lobos a las trampas. Es evidente el caso del Prau la Manga, a escasos metros del citado pozo de Los Molares. Otros ya son más dudosos, pues la misma estrategia de la I2Ov.).

1o Definición que toma prestada del tratado Origen y dignidad de la caza (Mateos I634, f. 
manga se sigue usando hoy para coger el ganado suelto por los puertos: serían los casos de La Mangada, La Manga'l Campón, El Camín de Mangas, La Manga y El Güerto la Manga.

\section{oso, osa, usil}

Algunos topónimos podrían referirse a las trampas para cazar osos. Podría ser el caso del pozo de Perabanes (en Cullapiuyu, en los altos de La Carisa), que según la tradición oral se empleaba para capturar estos animales. A un lado y a otro del Colléu La Cava, encontramos parajes relativos a la presencia del plantígrado a ambas partes del cordal: Brañaloso, en la vertiente de Lena, y El Trapón del Oso, en El Rasón, en la de Ayer. Entre ambos hallamos el pozo osero, en parte conservado. Como demuestran Torrente (I999, págs. I34-I4I) y Valverde (2009, pág. I50), los caleyos o loberas también podían emplearse para cazar osos. El pezugo, que veremos a continuación, era un tipo de trampa más específico para ellos.

Como en otros casos, tampoco tienen por qué estar directamente relacionados estos topónimos con pozos específicos, sino también con otro tipo de argucias para cazarlos, comenzando por la observación, seguimiento de guaridas, lugares de alimentos preferidos, pasos estratégicos, cortines de abeichas, truébanos, colmenas, etc., donde establecían sus esperas los lugareños, según la estación del año. O, simplemente, lugares de avistamiento frecuente.

Hay Valloseru, en los altos de Ventaniella (Ponga), donde había pasos del oso a los hayedos de Peloñu. El Penéu l'Osu, en Villayón; El Cantu l'Osu, en Casu, Brañagallones; Braña Usil, en los montes de Caliao, subiendo a Ruxecu, Ubales; L'Usil, sobre Carombu (Amieva); La Veiga Usil, en Cueiru (Teberga); La Piedra l'Osu, en Cuera, subiendo por Rozagás; La Canal del Osil, en Picos. Y tantos otros, como La Cuḷá 
l'Oso, El Vescón del Oso, La Sienda l'Oso, La Fonte l'Oso, Pumar de l'Oso, Cua la Osa, La Torre l'Oso, El Río l'Oso...

\section{pezugo, pesugo}

El pesugu, o presugu, es un tipo de prensa, del lat. prěmĕre 'apretar', pressam ('apretada, comprimida'), que se usaba para cazar osos; así los describe Madoz (I845, t. I, pág. 573) al referirse a uno localizado en Armenande (Allande): «consiste en una larga viga apoyada en una colmena y cubierta con un ramaje espeso, que forma una especie de caseta con solo una entrada, y por donde el oso descubre la colmena: este entra ansioso a apoderarse de aquella, y tan luego como la abraza y hace el esfuerzo natural para separarla de su sitio, se desploman la viga y caseta, quedando el oso a merced del cazador». No obstante, son trampas muy raras, de las que no quedan vestigios, salvo el referido Pezugo del Valle del Couso (Torrente, Llaneza y Álvares, 20I4, págs. 154-I55). Pudiera quedar una referencia toponímica en A Pena del Pesugo, en Pezós.

\section{porciles, porquera, porqueriza}

Todos ellos en relación con el asturiano porcín, porcinu, o puercu (lat. pŏrcum), en referencia a los xabalinos, los puercos salvajes. La palabra jabali, al igual que gochu, se introdujo tardíamente, por lo que es infrecuente. Un animal que debía ser muy espiado y perseguido, puesto que su caza suponía carne gratuita en abundancia. Por eso, los lugareños señalarían con sus nombres algunos parajes más frecuentados por los jabalís: cobijo, sesteo, lugares de cría o de simple paso; pero también aquellos puntos en los que resultaría más fácil su caza, con diferentes técnicas: lazos, redes, pozos y también en monterías.

Las Porqueras, Las Porquerizas, Porciles o Valporquero son nombres muy abundantes en casi todos los concejos. Otros, muy variados y más 
particulares: Los Porquirones (Quirós); La Ḷlama’l Puircu, Cochéu Puircu (Llena); Colláu Puercu, El Valle’l Puercu y Fuente'l Puercu (Casu); La Pena’l Porco y Río de Porcos (Ibias), entre tantísimos otros.

$$
\text { pozu, puzu, puzo, pozos }
$$

Tal vez sea la voz común con referencias más precisas a la trampa lobera. El Puzu los Lllobos está muy claro, por visible y bien conservado, en los altos de Xomezana (Ḷlena), bajo La Pena la Portieḷa, justo en el estrechamiento que forman las paredes casi verticales de la peña y las pendientes inferiores de la ladera abajo. Está bien conservado El Puzu los Lllobos del Blime, entre Las Navariegas de Riospaso y Teyeo (Ḷlena); o El Puzu los Ḷlobos de Armá, bajo El Soselllar (Llena), como se dijo. También El Puzu Reguirupuzu (tautoponímico), en Tablao (Ḷlena); El Puzo Viiyo, en los montes de Cuevas (Ayer); o El Puzu'l Llubu, en Lloreo (Mieres). Como estos, otros muchos en toda la geografía asturiana, que no enumeraremos.

Otros lugares como Pozu Valloberu (Sariego) pueden referirse también al lugar preciso de la trampa en un 'valle lobero'; Pozu Puercu (en Llavares, Santu Adrianu); y seguramente, también el El Puzu los Llobos (en la parroquia de Santa Bárbola, Samartín del Rei Aurelio). En el caso de Pozu Puercu (Santu Adrianu), el objetivo serían los xabalinos.

Más dudoso, El Pozu'l Can (también en Santu Adrianu). No obstante, una de las primeras referencias textuales a este tipo de trampas en Asturias podría encontrarse en un documento del monasterio de San Vicente, del año I0 58 en el que se alude a «illos pozos de canes» para delimitar los términos de una venta en Olivares, Oviedo (San Pedro, 2009, págs. 59-60) ${ }^{\mathrm{II}}$.

II «[...] de alia parte ad ocidentem per termino de Monnio, per illa castaniare quos plantauit Citi Menendizi usque in illos pozos de Canes, recta linea per medium illa quintana de Eita 
Abundan los Pozobal (Cangues d’Onís, Llanes, Llangréu, Mieres, Oviedo, Cabranes, Gijón, etc.), casi siempre 'pozo lobal', en interpretación lugareña. Del mismo modo, Tolívar Faes (1963, págs. 245-250) argumenta la existencia de un pozo de lobos (concretamente, se trataría de un caleyo) en términos de Pozobal, parroquia de San Pedro de los Arcos (Oviedo). Encontramos también Pozobal, junto al Pozu Caneyu (Cangues d'Onís) y el Mayéu Pozobal, próximo al desaparecido pozo lobal del Rañaúriu (Mieres). Empero, en otros lugares no habría que descartar un simple 'pozo del valle', como especifica el lugar de El Pozo'l Valle, en Piedramuelle (también en Oviedo); la interpretación popular habría convertido un simple pozo-val, en pozo-lobal, que les resultaría más familiar.

En otros casos, fue el propio pozo el que dio nombre al paraje donde se encuentra. Con el tiempo, estas construcciones fueron desapareciendo y los lugareños olvidaron su existencia. Sin embargo, el topónimo permite ahora adivinar su existencia. Es el caso, entre otros, de La Vega'l Puzu (Llena), donde aún se observa una hondonada mal conservada; el citado Reguirupuzu, también en Lena; El Monte'l Puzu (y quizás también El Monte'l Puzu Viiyu), en la parroquia de Bo (Ayer); y posiblemente también en alguno de los Prau'l Puzu (y otros similares), que encontramos en muchos concejos.

En estos parajes de tradición cinegética, el término "pozo» se refiere a la existencia de una trampa excavada (la construcción propiamente dicha). Ahora bien, no en todos los casos está claro el método de captura: en ocasiones el foso formaba parte de caleyos, mientras que otros se empleaban como trampas de cebo (Ordóñez, 20I7, pág. I.I78).

En otros muchos topónimos, los pozos pueden tener otras referencias $\mathrm{y}$ funciones: simples hondonadas del terreno, lugares donde se acumula

Agustinizi [...]» (Floriano, 1968, págs. 54-57), cit. por María Belén San Pedro (2009, págs. 59-60), que asocia la referencia a «illos pozos de Canes» con la presencia de un pozo para cazar lobos y lo pone en relación con aquel investigado por Tolívar Faes en Vallobín (1963, págs. 245-250) . 
el agua en el invierno, grietas, simas más o menos profundas, sumideros del agua, jous resguardados, guaridas de animales, lugares mitológicos o caleros artesanales. Sería el caso de El Pozu Barrosu, El Pozu Carbachéu, El Pozu Castro, El Pozu la Santa, El Pozu las Buitres y tantos otros con su adyacente (o adjetivo) para aclararlo.

\section{raposu, rapusu, raposa}

Hay muchas referencias a los raposos y raposas en la toponimia por cualquier concejo: como las formas de atraparlos eran muy diversas, en la mayoría de los casos, más que de vestigios sobre el terreno, ha de tratarse de zonas en la querencia de estos animales, muy vigiladas por los lugareños, que los cazaban allí con frecuencia. Es evidente el Colláu Zorru: altos de Peloñu (Ponga) muy estratégicos para estos animales en época de celo; allí acudirían de paso los nativos para su pequeño negocio de las pieles; se supone voz del portugués zorrar ('arrastrarse'), onomatopeya posible del 'roce' de estos animales cuando se pegan al suelo para camuflarse. Lugares como El Zorru (entre Sotres y Tielvi), La Zurruyera (Cabrales también), La Zorra (Tarna, Aller...), La Cueva la Zurra (Llanes), El Río'l Zurriacu (Valdés), La Zurruquera (Grao).

Para la otra base más frecuente, del lat. rapum 'rabo', en designación figurada por la forma de la cola, siempre más o menos esponjosa y reluciente, según sus tonos y cambios estacionales. La Raposera (Proaza, Uviéu), Las Raposeiras (Valdés), A Raposeira (Ibias), La Raposa (Piloña, Sariego, Villaviciosa), Les Raposeres (Santadrianu), El Raposeru (Llaviana), El Raposil (Amieva)...

\section{red, redal}

El empleo de redes para confeccionar trampas es ampliamente recogido en diversos tratados venatorios, como las «Monterías de Red» 
y de "Tela cerrada» del Discurso sobre el Libro de la montería (Argote, I582, caps. XXI-XXIII), también explicadas en los manuales de Mateos (I634, caps. XXIII-XXv) y Martínez de Espinar ([I644] I76I, caps. XIX y xx). Sin duda, se celebraban tanto en Galicia (Pérez, 20ı, págs. 259-26I) como en algunas partes de Asturias, tal y como documenta J. P. Torrente (1999, pág. 134), aunque de forma aislada en Grandas de Salime. Incluso, Valverde y Teruelo (200I, págs. 440-44I) demuestran el empleo mixto de piedra y redes (tensadas entre pilastras y arriostradas por un zócalo de mampostería), para formar las paredes del callejo de Valladares (Lugo).

Aunque apenas documentadas en Asturias, la caza con redes podría no ser tan excepcional. Topónimos como El Monte Redes (Caso), El Redal (Carreño), La Collada Reces (Ponga), Red (ya en la vertiente leonesa), conservan entre los lugareños larga tradición oral de trampas, pozos lobales, empalizadas, tejidos de varas... a la hora de atrapar animales diversos (Ordóñez, 2017, pág. I.I85).

\section{trapa, trapón}

A juzgar por el uso toponímico, la voz trapa tiene en el paisaje asturiano el mismo origen que trampa ('ardid engañoso, cepo'): se considera raíz prerromana, ${ }^{*}$ trapp-, tal vez de origen onomatopéyico, por el sentido primero de 'pisar, hacer ruido, crujir'; más tarde, 'atrapar la pisada, cepo'. El verbo atrapar ('coger por sorpresa, cazar') es un derivado del francés trappe ('trampa'), con esa pérdida de - $m$ - que funde ambas palabras: una trapa es una trampa. En usos toponímicos, aparece en lugares del monte frecuentados antes por animales salvajes, en los que se establecían pozos, garduñeras, armadijos y otras artes para cazarlos.

Esta interpretación ya la apuntaba Uría Ríu (1976, pág. 274), refiriéndose al Carril de la Trapa del Monte de Viduredo (Tineo), tomado del Libro de la Montería de Alfonso XI, pudiendo tener este signifi- 
cado $^{\mathrm{I} 2}$. Idéntica interpretación recoge Ramón d'Andrés en Sobrescobio para trapón ${ }^{13}$. Quizás el caso más evidente sea el de Campa Trapa, campera inmediata al antedicho pozo de Los Caleyinos, documentado desde I629.

Abunda el léxico toponímico en diversos concejos: La Trapa (Llanes, Cangues d'Onís, Ponga, Casu, Grau, Uviéu, Xixón, Llangréu, Ḷlena, Proaza, Salas, Palacios de Sil), referida a lugares más bien montaraces, prados, camperas; o con distintos matices morfológicos: El Trapellín (Ḷlena), La Trapielḷa (Degaña, Proaza, Llẹena, Colunga), La Trapetona (Llaviana), La Trapina (Mieres), El Trapón (Quirós, S. M. R. A.), La Trapona (Mieres). En otros casos, la palabra lleva otros núcleos referenciales o adyacentes: El Cantón de la Trapa, La Xerre la Trapa (Llanes), El Cantu'l Trapón (S. M. R. A.), Fonte A Trapa (Villayón), La Fonte la Trapa (Proaza), Garmas de la Trapa (Llanes), El Regueru la Trapa (Grau), La Trapa Dionisio (Llaviana), La Trapa Gobezanes, La Trapa Valdetañes (Casu).

Una vez más, en algún caso, cabría la homonimia toponímica: existe en asturiano la planta de la trapa, la yerba las culiebras (Helleborus foetidus L), usada para varios remedios caseros con los animales: depurativa, cicatrizante... Y un trampal es también un pequeño canal de agua en los regadíos (tsiviatso, aliviadero): una pequeña compuerta que se abría y cerraba, según las necesidades de riego.

\footnotetext{
12 «Veduledo, que es cabo Tineo, es buen monte de oso en todo tiempo; et son las vocerías, la una al Cabezo de Peña Vianda, et dende à Castañera fasta Nembredo el cerro Ayuso fasta el Agua de Marcia; et la otra por cima del cerro de la Barrosa fasta el Carril de la Trapa. Et son las armadas, la una en el carril de la Trapa, et la otra al lomo de la Trapa con la Barrosa» (Argote, 1582, fol. 4or).

${ }_{33}$ «En Sob. arrecuéyese trapón col significáu de «trampa para atrapar animales (lobos y osos normalmente) construida a base de unos palos atravesados por tapinos de hierba» (D'Andrés, I993, pág. II4).
} 


\section{Conclusiones}

Por lo dicho, creemos que el presente trabajo supone una etapa más en la investigación interdisciplinar del paisaje asturiano: cómo el análisis toponímico puede contribuir a la identificación y comprensión de diversos elementos patrimoniales en el entorno rural, de los que apenas queda memoria oral ni documental sobre su ubicación y forma de uso.

Hasta el momento, los estudios sobre trampas para la caza de fieras únicamente habían tratado los aspectos toponímicos y del paisaje de forma más o menos tangencial, exceptuando la minuciosa búsqueda toponímica que Luis Llaneza y Juan Pablo Torrente habían bosquejado en la Planificación del inventario y catálogo de estructuras cinegéticas históricas de Asturias (2000, págs. 23-4I). En cierto modo, nuestro trabajo de recopilación retoma y completa la tarea iniciada por dichos autores y va más allá, agrupando todos los topónimos por familias etimológicas y poniéndolos en relación con un campo léxico más amplio.

En cuanto a las fuentes consultadas, cabe resaltar la utilidad de los cuadernos de toponimia publicados por la Academia de la Llingua Asturiana. Esta colección constituye un útil inventario que facilita la búsqueda toponímica y garantiza la preservación de tantos nombres en peligro de extinción, algunos de ellos referentes a la existencia de trampas y a otros vestigios históricos. Esperamos que la continuación de esta serie pueda aportar aún más datos, puesto que solo se ha cubierto una parte del territorio asturiano, quedando decenas de parroquias pendientes de recopilación. No obstante, esta colección adolece de falta de precisión geográfica. Una sencilla georreferenciación (mediante coordenadas GPS) permitiría salvaguardar cada topónimo asociado a su emplazamiento exacto. De este modo, sería más fácil localizar los posibles vestigios, así como reconstruir y justificar el sentido de dichos topónimos en relación con el paisaje de su entorno (la etimología exacta). 
Por otra parte, los actuales visores cartográficos (accesibles on-line) ofrecen herramientas muy prácticas para la búsqueda toponímica. Sin embargo, las cartografías oficiales han padecido tradicionalmente dos problemas que debemos tener en consideración: la inexacta ubicación de algunos topónimos y, en muchas ocasiones, la disparidad entre el término recogido en el mapa y el topónimo real. Por todo lo anterior, el trabajo de campo se antoja imprescindible para solventar estos inconvenientes.

En definitiva, entendemos que la principal aportación de este trabajo ha sido recoger y organizar etimológicamente un importante número de topónimos alusivos a la actividad cinegética de los montes. Extraídas las semejanzas y los matices divergentes en los casos conocidos y estudiados in situ, intuimos unas estructuras rurales constructivas, un léxico y una toponimia que, creemos, podrían extrapolarse a otros parajes aún no visitados. En fin, un campo abierto al estudio multidisciplinar del paisaje, tanto en la vertiente humana como en la etológica, recogidas ambas a través de la memoria milenaria de los nombres de lugar.

\section{BIBLIOGRAFÍA}

Asturias (1974) = Junta General del Principado de Asturias, Ordenanzas Generales del Principado de Asturias (recopilación completa de las de 1494-I594-I659-I78I y 1805), Oviedo (Asociación de Bibliófilos Asturianos), 1974.

Argote (I582) = Gonzalo Argote de Molina, Libro de la monteria que mando escrevir el muy alto y muy poderoso Rey Don Alonso de Castilla y de Leon, vltimo de este nombre / acrecentado por Gonçalo Argote de Molina, Sevilla (Andrea Pescioni), I582.

Concepción (1990) = Xulio Concepción Suárez, «El lenguaje toponímico de origen animal», en Boletín del Instituto de Estudios Asturianos, 136 (1990), págs. 75I-767.

Concepción (20I7) = Xulio Concepción SuÁrez, Diccionario etimológico de toponimia asturiana, Oviedo (HiFer Editor), 2017.

D'ANDRÉs (1993) = RAMÓN D'ANDRÉs, Encuesta sociollingüistica nuna parroquia asturiana (Deva-Xixón), Uviéu (Universidá d'Uviéu, Serviciu de Publicaciones), 1993. 
Fernández (2006) = Margarita Fernández Mier, «La toponimia como fuente para la historia rural: la territorialidad de la aldea feudal», en Territorio, sociedad y poder, n. ${ }^{\circ}$ I (2006), págs. 33-52.

Floriano (i968) = Pedro Floriano llorente, Colección diplomática del monasterio de San Vicente de Oviedo (años 78I-I200), Oviedo (Instituto de Estudios Asturianos), 1968.

Friera (1994) = Florencio Friera Suárez, Toponimia . Conceyu de Sariego. Parroquia de Narzana, Uviéu (Academia de la Llingua Asturiana), I993.

García (1963) = Benjamín García Álvarez, Concejos de Parroquias de Asturias (especial referencia a las de Aller) y ordenanzas que regulan su organización y régimen, Pola de Lena, 1963.

Llaneza \& Torrente (2000) = Luis Llaneza \& Juan Pablo Torrente, Planificación del inventario y catálogo de estructuras cinegéticas históricas de Asturias, Oviedo (Consejería de Medio Ambiente del Principado de Asturias), 2000.

Madoz (I845) = Pascual Madoz, Diccionario geográfico-estadístico-histórico de España y sus posesiones de Ultramar. Madrid, I845. Tomo I.

Martínez ([1644] I76I) = Alonso Martínez de Espinar, Arte de ballestería y montería escrita con methodo para escusar la fatiga que ocasione la ignorancia, Madrid (Imprenta de Antonio Marín), I76I (fecha del original: I644).

Mateos (1634) = Juan Mateos, Origen y dignidad de la caça, Madrid (Imprenta de Francisco Martínez), i634.

Montero (1996) = Alberto Montero Prieto, El valle de Cuna a través de los tiempos, Mieres (A. Montero Prieto), 1996.

Moralejo (1977) = Abelardo Moralejo Laso, Toponimia gallega y leonesa. Santiago de Compostela (Editorial Pico Sacro), I977.

Ordóñez (20I7) = David Ordóñez Castañón, «Materiales y técnicas empleados en la construcción de antiguas trampas para la caza de fieras en la Montaña Central de Asturias", en Actas del Décimo Congreso Nacional y Segundo Congreso Internacional Hispanoamericano de Historia de la Construcción, Donostia-San Sebastián, 3 a 7 de octubre de 20I7, vol. II, págs. I.I77-I.I86.

Ordóñez \& Jové (20I5) = David Ordóñez Castañón \& Félix Jové Sandoval, "Los pozos de lobos en el concejo de Lena. Documentación, consolidación y puesta en valor del Puzu tsobos de Fidietso", en Mónica Alcindor i Huelva y Josep María Fortià i Rius (eds.), Arquitectura tradicional: essència o forma. Un debat obert al voltant de la intervenció a l'arquitectura vernacula. Actes del XXXVIIIè Curset. Jornades internacionals 
sobre la Intervenció en el Patrimoni arquitectònic, Barcelona (Col-legi d'Arquitectes de Catalunya), 2016, págs. 279-285.

Ordóñez y Nicolás (20I7) = David Ordóñez Castañón y Santos Nicolás Aparicio, «Los pozos !lubiles en Ayer (I. ${ }^{a}$ parte)», en Estaferia Ayerana; revista cultural del concejo de Aller, 18 (2017), págs. 20-35.

Pérez (2OIO) = David Pérez López, Os foxos do lobo: a caza do lobo na cultura popular, A Coruña (Editorial Canela), 2010.

Salvador \& Porcu (20io) = Eva María Salvador Fernández \& Chiara Porcu, En tierras de lobos: un estudio etnográfico y de patrimonio cultural en torno al lobo, Lugo (Ximena Galicia), 2010.

San Pedro (2009) = María Belén San Pedro, "Desarrollo diacrónico de un microespacio entre la Antigüedad y la Edad Media (siglos IV-XII): el actual área de El Cristo (oeste de Oviedo)", en Territorio, sociedad y poder n. ${ }^{\circ}$ 4, 2009, págs. 47-64.

Tolívar (1963) = José Ramón Tolívar Faes, «Un pozo lobal en Oviedo», en Boletín del Instituto de Estudios Asturianos n. ${ }^{\circ}$ 49, 1963, págs. 245-250.

Torrente (1999) = Juan Pablo Torrente, Osos y otras fieras en el pasado de Asturias, Proaza (Fundación Oso de Asturias), 1999.

Torrente, Llaneza \& Állvares (20I4) = Juan Pablo Torrente, Luis Llaneza \& Francisco Álvares, «Pièges historiques contre les loups et autres animaux sauvages dans la péninsule Ibérique», en Jean-Marc Moriceau (ed.), Vivre avec le loup? Trois mille ans de conflit, Paris (Éditions Tallandier), 20I4, págs. I42-162.

URÍA (1976) = JuAn URÍa Ríu, Los vaqueiros de alzada y otros estudios (de caza y etnografia), Oviedo (Biblioteca Popular Asturiana), 1976.

Valverde (2009) = José Antonio Valverde Gómez, Anotaciones al Libro de la Montería del rey Alfonso XI, Salamanca (Universidad de Salamanca), 2009.

Valverde \& Teruelo (200I) = José Antonio Valverde Gómez \& Salvador Teruelo Vizcaíno, Los lobos de Morla, Sevilla (Al Ándalus Ediciones), $200 \mathrm{I}$.

Villazón (1993) = Marta Villazón González, Toponimia. Conceyu de Villaviciosa. Parroquia de Pueyes, Uviéu (Academia de la Llingua Asturiana), 1993.

Vv. Aa. (I990-20I6) = Vv. Aa., Colección Toponimia, cuadernos del n. ${ }^{\circ}$ I al I42, Oviedo (Academia de la Llingua Asturiana), 1990-2016. 

